\title{
Benefit valuation for a Cost-Benefit Analysis in the context of developing nations
}

\author{
Evaluación de beneficios para un Análisis de Coste-Beneficio en el contexto de \\ naciones en desarrollo
}

Doi: https://doi.org/10.22458/rna.v1 1i2.3219

Dr. Luis Loría Rebolledo, L.E.

Health Economics Research Unit, University of Aberdeen, Scotland

luis.loria@abdn.ac.uk

https://orcid.org/0000-0002-1391-6478

Fecha de recepción: 14 de setiembre de 2020

Fecha de aceptación: 01 de octubre de 2020

\section{ABSTRACT}

Cost Benefit Analyses can be useful tools for the appraisal of infrastructure projects and policies. The literature and guidance documents on the application of the CBA methodology are extensive. Moreover, the vast majority of this literature is focused on applications in upper and upper-middle countries (developed nations). This paper adds to this literature by exploring the issues of undertaking a benefit valuation exercise, as part of a CBA, in the context of developing nations. It provides an overview of the different methodologies to value benefits and offers guidance on some of the issues that may arise when such methodologies are implemented in a developing nation. This paper also offers general guidance to ensure a benefit valuation exercise provides a helpful tool to appraise a project in the context of a developing nation.

\section{RESUMEN}

Los Análisis de Coste-Beneficio pueden constituir herramientas útiles para la valoración de proyectos y políticas de infraestructura. La literatura y los documentos de orientación sobre la aplicación de la metodología ACB son extensos. Además, la gran mayoría de esta literatura está centrada en aplicaciones en países de ingresos altos y medio altos (naciones desarrolladas). Este ensayo se suma a dicha literatura al examinar los problemas relacionados con emprender un ejercicio de evaluación de beneficios, como parte de un ACB, en el contexto de naciones en desarrollo. Ofrece una visión de las diferentes metodologías para valorar los beneficios y proporciona una orientación sobre algunos de los problemas que pueden surgir al momento de implementar esas metodologías en una nación en desarrollo. Este ensayo también ofrece una orientación general para asegurar que un ejercicio de evaluación de beneficios provea una herramienta útil para valorar un proyecto en el contexto de una nación en desarrollo.

\section{RÉSUMÉ}

Les Analyses de Coût-Bénéfice peuvent constituer des outils utiles pour l'évaluation de projets et de politiques d'infrastructure. La littérature et les documents d'orientation sur l'application de la méthodologie ACB sont vastes. En outre, la grande majorité de cette littérature est centrée sur des applications dans des pays aux revenus élevés et moyennement élevés (nations développées). Cet essai s'ajoute à cette littérature en examinant les problèmes d'effectuer un exercice d'évaluation de bénéfices, faisant partie d'un ACB, dans le contexte de nations en développement. Il offre une vision des différentes méthodologies pour évaluer les bénéfices et donne une orientation sur certains problèmes qui peuvent surgir au moment d'appliquer ces méthodologies dans une nation en développement. Cet essai offre également une orientation générale pour assurer qu'un exercice d'évaluation de bénéfices fournisse un outil utile pour évaluer un projet dans le contexte d'une nation en développement.

\section{RESUMO}

A análise de custo-benefício pode ser uma ferramenta útil para avaliar projetos e políticas de infraestrutura. A literatura e os documentos de orientação sobre a aplicação da metodologia CBA são extensos. Além disso, a grande maioria desta literatura está focada em aplicações em países de renda alta e média alta (nações desenvolvidas). Este ensaio acrescenta-se a essa literatura ao examinar os problemas relacionados com empreender um exercício de avaliação de benefícios, como parte de um CBA, no contexto das nações em desenvolvimento. Ele oferece uma visão das diferentes metodologias para avaliar os benefícios e fornece uma orientação sobre alguns dos problemas que podem surgir ao implementar essas metodologias em uma nação em desenvolvimento. Este ensaio também oferece uma orientação geral para garantir que um exercício de avaliação de benefícios forneça uma ferramenta útil para avaliar um projeto no contexto de uma nação em desenvolvimento.
KEY WORDS:

PUBLIC POLICIES, INFRASTRUCTURE POLICIES, DEVELOPING NATIONS
PALABRAS CLAVE:

POLÍTICAS PÚBLICAS,

POLITICAS DE INFRAE-

STRUCTURA, NACIONES

EN DESARROLLO
PALAVRAS CHAVE:

POLÍTICAS PÚBLI-

CAS, POLÍTICAS DE

INFRAESTRUTURA

NAÇÕES EM DESEN-

VOLVIMENTO
MOTS CLÉS:

POLITIQUES PUBLIQUES, POLITIQUES D'INFRA STRUCTURE, NATIONS EN DÉVELOPPEMENT. 


\section{INTRODUCTION}

A Cost-Benefit Analysis (CBA) offers an analytical and systematic mechanism to decide and inform the undertaking of a project (Layard, 1994). The premise of a CBA, a subtraction of the value of benefits minus the costs, is relatively simple. Moreover, the valuation exercise needed for a CBA can be a complex undertaking (Ray, 1990). This complexity stems for the fact that this exercise must account for all possible direct and indirect items, which often includes externalities (Hanley, 1996). The valuation of costs is relatively simpler, as they are typically made up of goods and services that are frequently traded. Benefits, on the other hand, are more difficult as it involves placing monetary values on goods that often are not traded in formal markets. For example, it can be difficult to place a value to an hour of travel time or to a reduction in local pollutants. Benefit valuation therefore requires non-market valuation techniques.

Non-market valuation techniques typically follow the same principles across disciplines (Hanley, 1996). In that sense, the literature has benefited from multi- and interdisciplinary research in fields such as transport, environment, health and marketing. This in turn has fostered the development of guidance documents that can inform the application of non-market valuation and, more generally, CBAs (Pearce, Atkinson, Mourato, 2006, Warner, 2010, Sartori, Catalano, Genco, Pancotti, Sirtori, Vignetti, 2020). Moreover, while guides can be useful to provide the theoretical grounding for the application of non-market valuation, there are practical and contextual implications that are worth considering when applying these to infrastructure projects or policies in different countries. Specifically, the majority of guides and, more generally, the literature, focus on applications based in high and upper-middle income countries. Guidance specifically based on the context of developing nations is relative scarce (Caroline, Dinwiddy, 1996, Quah, 2013).

It is expected infrastructure expenditure in developing nations will increase over the next years. In order to ensure these projects and policies are well designed and provide the intended benefits to society, they need to be subject to rigorous appraisal processes that reflect the local context (Warner, 2010, Sartori, Catalano, Genco, Pancotti, Sirtori, Vignetti, 2014). A mechanism to ensure this is undertaking quality CBAs as part of the design and appraisal process. The context of developing nations can vary dramatically from that of more developed nations (Pearce, Atkinson, Mourato, 2014; Pearce, Pearce, Palmer, Valuing, 2002; Abelson, 1996). Many suffer from structural governance issues, ranging from weakened institutions to a lack of public trust. Their macroeconomic performance is often very different from that of developed nations, with much more pronounced and unstable economic cycles, and, usually, reduced financial resources. From a societal perspective, there are usually high levels of inequity and overall less access to information. These conditions make developing nations particularly vulnerable to the approval of ill-designed or, even, pork barrel projects or policies. In this sense, existing CBA guidance may fall short of the needs of developing nations.

This paper will draw upon existing guidance and literature on benefit valuation for CBA, and discuss some of the issues that are likely to arise when using these techniques in the context of a developing nation. It will also offer guidance to overcome some of the issues and ensure the valuation exercise, and overall CBA delivers on its intended aims and objectives of ensuring infrastructure projects are well done. The paper is set out as follows: provide an overview of benefit valuation, a review of issues specific to methods to benefit valuation, guidance on the methods to aggregate these values for a CBA and an discussion of general issues regarding benefit valuation (and CBA) and a conclusion.

\section{Overview of benefit valuation}

Non-market valuation is concerned with the value of goods and services that are not traded in formal markets. Thus, it uses economic methods to infer the individual values and provide a monetary value that can be used as part of CBA or valuation exercise. The value of a non-market good is derived from welfare economics and particularly, theory of value. Welfare economics' main goal is to measure the well-being individuals, which in turn depends on 
their consumption of goods and services. A premise to achieve this is that individuals are the best judge of how well off they are in a particular situation and that welfare inferences can be made from the individual's consumption decisions (Freeman, Herriges, Kling, 2014).

The valuation of a good (such as a benefit) is based on the intrinsic value that the individual places on it. The individual's preferences can be obtained by eliciting how much they are willing to pay (WTP) in monetary terms for the benefit they obtain from the good or how much they are willing to accept (WTA) a forego a benefit or incur a loss. If the levels of provision of the good are changed, the individual will vary its expenditure to stay indifferent in terms of welfare. Changes in price and quantities of the good can in turn be used to observe the WTP and WTA and elicit the economic value of the good. Thus, the individuals' reactions to changes in prices and quantities of a good can be used to estimate welfare changes.

When individuals cannot adjust their consumption, consumer surplus measures are used. Hicks (1943) redefined consumer surplus and suggested four alternative measures of welfare gain that hold utility constant: compensating variation, equivalent variation, compensating surplus, and equivalent surplus (Hicks, 1943). They differ depending on which level utility is held constant (initial or another level) and on the consumers' property right with the good in question. Welfare economics and benefit valuation aims to measure these Hicksian welfare measures and, overall, consumer surplus. Economists have a set of empirical tools to measure this, which observe choices to reveal information about people's preferences.

\section{Methods of benefit valuation}

Non-market valuation methods can be categorised into two main types: revealed and stated preference. Revealed preference methods rely on observational (and existing) data from formal markets to infer goods and services' values. These methods assume individual values can be elicited from market transactions. There are three main approaches: hedonic price, travel cost and averting behaviour. Hedonic price uses transactions of a specific market good to extract individual values using statistical methods (Rosen, 1974). The most common application of this method is using real estate data. For example, the value of proximity to a park can be inferred from property prices. Travel cost method uses a similar approach and infers values from data about travel costs to a particular site (Champ, Boyle, Brown, 2003). The idea being that the value can be inferred from how much a person spends to visit a site. This approach is, however, limited to recreational use values. Averting behaviour, which sometimes is considered as a special kind of hedonic pricing, elicits values from transactions that are meant to prevent or protect from an adverse effect (WB, 2002; Dickie, 2017). These observed transactions thus reveal the value of avoiding said event or externality. For example, purchasing personal protective equipment to prevent a work-related injury.

The main advantage of revealed preference methods is that they use transaction data from formal markets and therefore rely on observed behaviour. However, revealed preference is prone to endogeneity, multi-collinearity and omitted variable bias, which make the inference of individual values difficult. In other words, the individual effect cannot be properly separated from the transaction data. These limitations can be dampened using more (complementing) data and more advanced econometric models. Moreover, this requires the existence and access to comprehensive and reliable datasets, which can be often difficult to find in developing nations. In some cases, it is not uncommon to find incomplete or missing accounting in financial, labour and commodity markets, which can even further magnify the limitations of revealed preference methods. The reason for the lack of information can be structural or even political. Other assumptions of revealed preference methods, such as access to perfect information for the economic agents are limited in developing nation contexts. For example, lack of knowledge of the risks from a dangerous workplace. 
Stated preference methods make use of people's reported behaviour. This method uses survey to directly ask people or implicitly elicit their values for the goods and services (i.e. benefits) that wished to be valued (Johnston, Boyle, Adamowicz, Bennett, Brouwer, Cameron, et al, 2017). There are different methods, such as contingent valuation and choice experiments. Contingent valuation directly asks people for a monetary value (Carson, 2012). Choice experiments asks people to choose between different bundles of goods and uses the trade-offs for each of the attributes that make up the bundles to estimate monetary values as marginal rates of substitution (Hoyos, 2010; Hanley, Mourato, Wright, 2001). Amongst choice experiments, these can be either discrete (where respondents choose one alternative) or ranking (where respondents rank the alternatives.

Stated preference has the advantage that they can focus on the valuation of a specific good or service. They do not have to infer values from existing data, thus avoiding the multicollinearity limitations of revealed preference methods. They can also be used to elicit values for non-use values of goods or services (i.e. things which the respondent will never get to make use of) or goods that do not yet exist. Moreover, given stated preference is not based on observed behaviour; it is prone to hypothetical bias and other methodological implications that if not accounted for can lead to unreliable data (Diamond, Hausman, 1994). Furthermore, the success of a stated preference study is dependent on a robust survey instrument. This often requires the work of a multidisciplinary team that focuses on survey development and administration. Stated preference studies are context dependent and thus it is unlikely a same study (e.g. survey instrument) can be repeated across different settings. Stated preference methods are therefore resource intensive.

The context of developing nations can increase the limitations of stated preference and thus require special consideration (Hanemann, 1999). The design and implementation of stated preference usually requires specialised knowledge that is not often found in developing nations. While outside experts can help design the study, likely there will be a need for local collaboration. The context on which the survey will be implemented must be taken into account. For example, there is a need for local expertise in the community to find ways to adapt the survey instrument to the local setting so that potential sources of bias (sample-selection, interviewer, mode, etc.) are minimised. The survey instrument must also ensure there is incentive compatibility. Mechanisms typically identified in the literature to ensure respondents answer in their best interest and feel engaged with the survey might need to be adapted to the local context. Payments vehicle might need to be adapted to the local context. Hypothetical bias mitigations (cheap talks, consequentiality scripts, etc.) need to reflect the setting of the community. These adaptations require in depth knowledge of the sample characteristics and thus will benefit from the collaboration of local officials. At the same time, it can be expensive to implement a stated preference study. This can be a limitation when financial resources to develop a project are scarce. Practitioners should ensure stated preference methods are used only when there are enough resources to undertake a good quality study.

There are two other, albeit less used, approaches should revealed or stated preference not be possible. The first alternative approach is to use avoided costs. This quantifies the benefits in terms of the no consumption of substitute good (Hanley, 1999). While it might no be appropriate in many cases, it is an alternative when such a proxy good can be used. For example, the avoided cost of transporting residual water from a community with no sewage infrastructure. It is important to ensure the avoided cost corresponds to an actual substitute of the good's benefit being valued. This approach also requires the existence of formal and functioning markets for the goods for which the avoided cost is being measured. In developing nations there might be no such markets or there might be market distortions that make this approach difficult to use.

The second, alternative, approach is to quantify benefits in terms of (expected) value added. This quantifies the benefits in terms the expected gains for users. For example, increased worker productivity from the implementation of improved Internet connectivity in a region (Sartori, Catalano, Genco, Pancotti, Sirtori, Vignetti et al, 2020). 
This approach involves looking at experiences for other countries and settings to draw an estimation of what the benefits of a project would be. As with the avoided costs, this could be impacted by potential market distortions. Furthermore, this approach is susceptible to the same limitations of revealed preference. For example, for the Internet connectivity case, gains in productivity will likely be affected by other factors. The practitioner must ensure they are able disentangle these effects. This might not be possible in the absence of comprehensive data. Similarly, care should be taken when estimating the potential benefits from a project that was done in another (from a more developed country) context.

There exists another method to conduct non-market valuation, which is to use value or benefit transfer. Benefit transfer involves taking values from another project and adapting them to the local context (Hanley, 1992; Rolfe, Windle, Bennett, Benefit, 2015). This approach is used when it is not possible to obtain valuation measures directly from the users (using the methods described above). Sometimes benefit transfer is not considered one of the main types to undertake benefit valuation, as the original values being transferred will likely have been obtained using revealed or stated preference, but benefit transfer offers a practical and less expensive approach to value benefits. This approach is, however, still relatively new and has therefore been less explored in the literature. This is particularly important when dealing with transfers between developed and developing nations.

The literature has found that valuation measures in developing nations are typically lower than in developed nations (Whittington, 2010). Given the majority of studies (and projects) dealing with benefit valuation are published in the context of developed nations, most value transfers will likely happen from an upper-income nation to a lower-income nation setting. Benefit transfer will then require adjusting existing values from one setting to another. The adjustment should be done to accommodate the specifications of both the project and the setting. Appropriate adjustment measures should be used. For example, only adjusting using gross national product per capita might not be enough when dealing with countries with vastly different societal inequalities. The transfer process should endeavour to account for a number of socio-demographic characteristics of the users. Furthermore, the source data's quality and reliability is key. Practitioners should compile data from published studies and conduct a review to focus on those with settings as close as possible as the one where it is to be implemented. This requires a comprehensive characterisation of both the source and target setting. This might be an issue in the context of lack of data in developing nations.

\section{Aggregating the benefit values}

Once benefits have been quantified, these need to be entered into the CBA calculation. This step again will require some additional considerations when dealing with developing nations. First, practitioners must ensure there is no double counting. This is especially the case for projects with many types of benefits (as it is in the vast majority of cases) and for which different approaches have been used. Double counting is also common when indirect and secondary markets are considered in the benefit valuation. An example of double counting would be when added value of commercial property is counted together with increased sales in the property. Transactionally, the two are mutually exclusive and thus must not be included together. Similarly, labour from project construction typically should not be included as a benefit, as the benefits to society are usually already captured through other economic values in the benefit exercise. While the methodological steps to avoid double counting are the same irrespective of the context of the project, the importance of this issue becomes salient when focusing on the motivations behind a project. Double counting is a common issue when trying to justify pork barrel projects. Developing nations, especially those with weakened institutional and political structures, can be prone to the advancement of pork barrel projects using overestimated benefits. Practitioners and reviewers should thus pay special attention to the issue of double counting when conducting a benefit valuation exercise or project appraisal. 
Another issue, particularly relevant for developing nations, relates to the monetary unit used for the valuation and, specifically, on the use of exchange rates. Typically, in developing nations valuation exercises are done in terms of a hard currency (e.g. United States Dollar, Great British Pound, Euro, etc.). Developing nations usually have soft currencies, which are susceptible to cyclical fluctuations. Given the analysis of infrastructure projects is over long lifespans, any currency fluctuation (e.g. devaluation) could impact the findings and, in extreme cases, the conclusions of a CBA exercise. When the benefit valuation is done in a non-national currency or there are values in different currencies, practitioners should aim to use historical and/or forecast exchange rates from official central financial institutions. Ideally, a sensitivity analysis of exchange rate fluctuations should be undertaken to explore the implications on the CBA findings and conclusions.

Non-market valuation of benefits involves estimating values over different periods of time, which need to be aggregated to conduct the CBA exercise. Bringing these values to a specific point in time (i.e. typically present value) involves discounting. The choice of discount factor raises both methodological and ethical issues. There is uncertainty on what the time horizon for a project will be and the discount rate to use. For example, there is a question of how long should the benefits in terms of reduced greenhouse gas emissions for environmentally focused projects be measured for. Similarly, if societal benefits are to be measured, then social discount rates should be used. The majority of guidance of discount rates focuses on developed nations, which has implications if used for developing nations. High discount rates minimise future benefits, and costs. This can be an issue considering projects with high maintenance costs. Practitioners should use local guidance in terms of which discount rate to use. If no guidance exists, practitioners should engage with local stakeholders to discuss the context of the project and agree on a discount rate that reflects the needs and capabilities of the nation. Furthermore, there has also been recent discussion that goes beyond fixed discount rates and instead proposes the use of time-varying discount rates or multiple discount rates for different benefit values.

A benefit valuation, and CBA exercise, will also need to deal with the uncertainty of any infrastructure project. The estimation of non-market benefit values is uncertain by nature. This uncertainty can be in the form of the actual benefit value and also in how the value is achieved over time. While uncertainty can be accounted for using sensibility analysis, there are questions of how to set the parameters of this analysis. Typically, past experience will offer some guidance to design the sensibility analysis. Guidance suggests that sensitivity analysis for the benefits, and costs, needs to model reasonable scenarios (Gollier, 2013; Hamilton, Clemens, 1999). Moreover, in developing nations, its likely similar projects have never or seldom been done before, thus it is difficult to ascertain what is a reasonable scenario is in the local context. In other words, what is reasonable in a developed nation might not be in a developing one (i.e. economic growth, macroeconomic performance, etc.). The sensitivity analysis should then, ideally, model extreme scenarios that ensure the robustness of the CBA findings in the local context. As more projects are undertaken, subsequent uncertainty analysis can be adjusted to reflect on the local experience and define what is reasonable and not for a given setting.

\section{General issues with benefit valuation.}

As it has been outlined in this paper, CBAs, and benefit valuation, are subject to numerous assumptions and choice of methodologies. Practitioners should err on the conservative side and ensure these decisions do not result in an overestimation of benefits. In other words, choice of methods and their assumptions should not be done to systematically favour the project. CBAs are not just decorative exercises to be undertaken as part of a project checklist process. They are done to inform the convenience and design of an infrastructure project or policy. Policymakers must then ensure that CBAs are done with validated and robust methodology. This is of particular importance in the setting of developing nations, where it is likely similar projects are rare and/or there are structural institutional challenges that make independent project appraisal difficult. Thus, CBAs should undergo a peer-review process from an independent reviewer to ensure their methodological rigor. The reviewers' role overall is to ensure the qua- 
lity of the CBA. This review should be multidisciplinary and undertaken by an independent party with no conflict of interest or incentive that may influence the conclusions of the CBA. They must verify the assumptions; make sure the methods are applied based on accepted theoretical and practical methods; and replicate the results using these. It is important this review is completely independent to the parties interested in the outcome of the CBA analysis. Independent reviewers must also be familiar with the topic and methods. In the case of developing nations, this might require international or foreign participation.

Another way to ensure the quality of a CBA, and its benefit valuation exercise, is to ensure its transparency. This means making the CBA methods and underlying the data available to third parties and the public. This open access could facilitate local authorities to collaborate with independent researchers and academic institutions in the review and the overall project appraisal. At the same time, this could bring about synergies that allow institutions to build capacity with local professionals. In the case of developing nations, where this type of projects are relatively scarce, open access to project appraisals can help act as case studies to build the local expertise and create expertise networ$\mathrm{ks}$ in areas that go beyond the benefit valuation exercise itself. It is also a way to build public trust and facilitate the communication of the benefits of an infrastructure project or policy. Benefit valuation must be as transparent and special care should be taken to ensure its accessibility.

Benefit valuation exercises must adapt both the project and nation's context. While existing guidance can serve as a template to undertake these exercises, the choice of methodology and its parameters must reflect to the nature of the project. When it comes to the type of benefit valuation approach used, this might involve trading off direct methods (such as revealed and stated preference) with value transfer methods. There is no one right choice of method. It will be dependent on the resources and, crucially, context of the type of value within the project. A benefit value that is key to the conclusions of the CBA requires a more robust method than one that is only marginally important. For example, benefits from value of time in a transport project are expected to be the most significant contribution to the overall benefits, therefore their calculation should be done using more advanced methods. At the same time, while the use of a resource intensive approach, such as stated preference, can be initially prohibitive; local authorities must also weigh the fact that this type of studies could be used to inform values for multiple projects. For example, a robust study to estimate value of time could be used to inform multiple transport infrastructure projects. Furthermore, values obtained from a direct method, if possible, should be compared and validated against existing values. These values, preferably, would be from local and robust studies. In some cases, it will not be possible or feasible to use direct methods (as part of a revealed preference or stated preference study). Values obtained from benefit transfer must be adjusted to the local context. Practitioners must avoid simply assuming two countries (or contexts) are similar enough to justify a value or proxy. These should be adjusted using criteria obtained from official sources and/or local research. Furthermore, in the context of developing nations, this process will likely require the use of multiple adjustment measures. Any value transfer should be complemented with a robust sensitivity analysis.

There are also political and structural issues worth discussing when conducting a benefit valuation in the context of a developing nation. The presence of weakened institutions or regulatory bodies could have an impact on the choice of methodology and, even, the overall conclusions. For example, an overburdened or ineffective regulatory body may delay the issuance of necessary permits required for the project, thus affecting the timeline of the estimated values. These types of structural issues, and how they translate to potential uncertainties in the valuation process, must be explored at length with local stakeholders. It is key this process is carried out transparently. Stakeholders, and the wider public, must be able to not only access, but also understand the assumptions and methods behind the valuation exercise. The stakeholder engagement must shape and inform the valuation process, not just act as a dissemination exercise. Furthermore, it would be expected that institutional learning will occur as more projects, and their respective valuation exercises, are undertaken. Increased institutional learning, and added capacity building, will reduce the uncertainty these issues could have in the valuation and project appraisal process. 
Also related to potential structural issues of developing nations, is the topic of societal inequities. Current CBA guidance is based on case studies in nations with relatively low societal inequalities (at least compared to developing nations). This has implications not only on how benefits are distributed amongst users, but also, crucially, how these should be quantified in a valuation exercise. A possible way to account for this is using weights to allocate potential benefits within the society. This, however, brings about methodological challenges and the potential of either biasing the findings or, in the case of weakened institutions, encourage these biases to favour a particular policy or project. The issue of equity, in the context of developing nations, is an on-going one that requires more research. A way to do put this research into practice, for example as part of a case study, is to ensure project appraisals are done with transparency and with independent peer-reviews to ensure their quality.

\section{CONCLUDING REMARKS}

Benefit valuation is a key component to CBA analysis. The majority of literature, and guidance that stemmed from it, has however focused on applications in upper and upper-middle countries. This is a limitation, given the importance and frequency with which these types of analyses are likely to happen as developing nations engage in more infrastructure projects. This paper has outlined some of the implications of key features of benefit valuation when applied in developing nations. In sum, benefit valuation exercises are multidisciplinary tasks that require methodological rigor and, crucially, adapt to the local context. The choice of methods and underlying assumptions must reflect the project's nature and the local setting. A good quality benefit valuation exercise, and overall CBA, will require an independent peer review to ensure the methods are applied correctly. The undertaking of rigorous benefit valuation can act as learning mechanisms to increase local capacity building. The recommendations in this paper are intended to ensure CBA valuation is not only an academic exercise, but actually ensure projects are well done and they deliver the intended benefits to society

\section{REFERENCE}

Abelson P. Project appraisal and valuation of the environment: general principles and six case-studies in developing countries.: Springer; 1996.

Caroline D, Dinwiddy CL, Teal FJ. Principles of cost-benefit analysis for developing countries.: Cambridge University Press; 1996.

Champ PA, Boyle KJ, Brown TC, Peterson LG. A primer on nonmarket valuation.: Springer; 2003.

Diamond PA, Hausman JA. Contingent valuation: is some number better than no number? Journal of economic perspectives 1994;8(4):45-64.

Dickie M. Averting behavior methods. A Primer on Nonmarket Valuation: Springer; 2017. p. 293-346.

Freeman III AM, Herriges JA, Kling CL. The measurement of environmental and resource values: theory and methods.: Routledge; 2014.

Gollier C. Pricing the planet's future: the economics of discounting in an uncertain world.: Princeton University Press; 2013.

Hanley N, Spash C. Cost benefit analysis and the environment. 1996.

Hanley N, Mourato S, Wright RE. Choice modelling approaches: a superior alternative for environmental valuatioin? Journal of economic surveys 2001;15(3):435-462.

Hanley N. Are there environmental limits to cost benefit analysis? Environmental and Resource Economics 1992;2(1):33-59.

Hanemann WM. The economic theory of WTP and WTA. Valuing environmental preferences: Theory and practice of the contingent valuation method in the US, EU, and developing countries 1999:42-96.

Hausman J. Contingent valuation: from dubious to hopeless. Journal of Economic Perspectives 2012;26(4):43-56. 
Hamilton K, Clemens M. Genuine savings rates in developing countries. The World Bank Economic Review 1999;13(2):333356

Hicks JR. The four consumer's surpluses. The review of economic studies 1943;11(1):31-41.

Hoyos D. The state of the art of environmental valuation with discrete choice experiments. Ecol Econ 2010;69(8):15951603.

Johnston RJ, Boyle KJ, Adamowicz W, Bennett J, Brouwer R, Cameron TA, et al. Contemporary guidance for stated preference studies. Journal of the Association of Environmental and Resource Economists 2017;4(2):319-405.

Layard PRG. Cost-benefit analysis.: Cambridge University Press; 1994.

Ray A. Cost-benefit analysis: Issues and methodologies.: The World Bank; 1990.

Rosen S. Hedonic prices and implicit markets: product differentiation in pure competition. Journal of political economy $1974 ; 82(1): 34-55$.

Rolfe J. Theoretical issues in using choice modelling data for benefit transfer. Choice modelling and the transfer of environmental values $2006 ; 1: 28-51$.

Rolfe J, Windle J, Bennett J. Benefit transfer: insights from choice experiments. Benefit Transfer of Environmental and Resource Values: Springer; 2015. p. 191-208.

Sartori D, Catalano G, Genco M, Pancotti C, Sirtori E, Vignetti S, et al. Guide to cost-benefit analysis of investment projects. Economic appraisal tool for Cohesion Policy 2014;2020.

Pearce D, Pearce C, Palmer C. Valuing the environment in developing countries: case studies.: Edward Elgar Publishing; 2002.

Pearce D, Atkinson G, Mourato S, Carson R Cost-benefit analysis and the environment: recent developments.: Organization for Economic Co-operation and development; 2006. Contingent valuation: a comprehensive bibliography and history.: Edward Elgar Publishing; 2012.

Quah E. Cost-Benefit Analysis in Developing Countries. The Globalization of Cost-Benefit Analysis in Environmental Policy 2013:19.

Warner AM. Cost-benefit analysis in World Bank projects 2010.

World Bank. Willingness to pay for reduced morbidity. Unpublished manuscript prepared for the workshop,"Economic valuation of health for environmental policy: assessing alternative approaches; 2002.

Whittington D. What have we learned from 20 years of stated preference research in less-developed countries? Annu. Rev. Resour. Econ. 2010;2(1):209-236. 